\title{
Natascha Bagherpour-Kashani, Thomas Stöllner (eds.). Water and caves in Ancient Iranian religion: Aspects of archaeology, cultural history and religion
}

\section{Rémy Boucharlat}

\section{(2) OpenEdition}

\section{Journals}

Édition électronique

URL : http://journals.openedition.org/abstractairanica/41184

DOI : 10.4000/abstractairanica.41184

ISSN : 1961-960X

Éditeur :

CNRS (UMR 7528 Mondes iraniens et indiens), Éditions de l'IFRI

Référence électronique

Rémy Boucharlat, « Natascha Bagherpour-Kashani, Thomas Stöllner (eds.). Water and caves in Ancient Iranian religion: Aspects of archaeology, cultural history and religion », Abstracta Iranica [En ligne], Volume 34-35-36 | 2017, document 9, mis en ligne le 15 juillet 2016, consulté le 02 octobre 2020. URL : http:// journals.openedition.org/abstractairanica/41184; DOI : https://doi.org/10.4000/abstractairanica. 41184

Ce document a été généré automatiquement le 2 octobre 2020.

Tous droits réservés 


\title{
Natascha Bagherpour-Kashani, Thomas Stöllner (eds.). Water and caves in Ancient Iranian religion: Aspects of archaeology, cultural history and religion
}

\author{
Rémy Boucharlat
}

\section{RÉFÉRENCE}

Natascha Bagherpour-Kashani, Thomas Stöllner (eds.). Water and caves in Ancient Iranian religion: Aspects of archaeology, cultural history and religion. Workshop in the " Kunstsammlungen » at the University of Bochum, 2008. Reimer, 2011, p. 1-168. (AMIT, 43)

$1 \quad$ La moitié de ce volume d'AMIT est consacrée à la publication d'un Workshop sur la découverte étonnante en 2001 de témoins matériels de rituels anciens dans la mine de cuivre de Čāle Ġār, près de Vešnave, sur le plateau Iranien, entre Qom et Kāšān. Un programme conjoint de l'ICAR et de l'Institut archéologique allemand, a été mené depuis 2001, y compris des fouilles, jusqu'en 2005, avec le soutien de la Deutsche Forschung Gemeinschaft. La réunion rassemblait une dizaine de savants, les uns archéologues, les autres spécialistes des religions.

2 Par les premières reconnaissances puis par les fouilles, ce sont quelques 10000 artefacts qui ont été relevés en deux points des grottes, pour la plupart dans l'eau qui manifestement a tenu un rôle très important dans ce lieu objet de rituels. La destruction de ces dépôts paraît intentionnelle. Les objets sont des céramiques, 140 anneaux, boucles d'oreilles, plus de 1300 perles, pendants et amulettes. Th. Stöllner, A. Abar, N. Bagherpour présentent ces découvertes dans des contributions séparées. De 
plus, Le milieu a permis la conservation exceptionnelle de matériaux organiques, bois, grains, fruits. La poterie, bols, cruches, gourdes, pots, se rapporte à l'âge du Fer tardif (VIII ${ }^{-}-\mathrm{VII}^{\mathrm{e}}$ s. av. J.-C.), mais surtout à la fin de l'époque achéménide et au-delà (céramique peinte) jusqu'au début de l'époque islamique. Quelques monnaies confirment l'activité des grottes entre la période parthe et le début de l'Islam.

La contribution de D. Huff (p. 79-111) ne porte pas sur l'ensemble de Vešnave, mais sur deux exemples de «trésors » d'objets d'époque sassanide, dont la fonction est disputée. L'ensemble trouvé par l'auteur dans la cour intermédiaire du Qal'e DoĤtar de Fīrūzābād consiste en pierres semi-précieuses, sculptures miniatures et deux monnaies; ce ne serait pas un dépôt de fondation, comme on en connaît à l'Āpādānā de Persépolis, mais un lieu où aurait été perdu un mobilier précieux lors d'une attaque. En revanche, les plaques votives dont certaines sont figuratives, trouvées dans l'angle de la cour précédent le sanctuaire du feu de TaHt-e Soleymān, seraient quant à elles des marques de dévotion. Quant au trésor de l'oxus et au trésor de Bactriane qui marquerait la longue tradition de ce type d'offrandes, l'absence de contexte archéologique de ces découvertes non contrôlées incite à ne pas spéculer sur leur fonction précise. L'article de B. Overlaet (p. 113-139) est également fondé sur des comparaisons, des ensembles métalliques de l'âge du Fer trouvés au Luristan, le trésor de Kalmākare, essentiellement des vases en métal, les dépôts de Sangtarāšān, ainsi que le matériel du temple(?) de SorHูdom-e Lorī. Pour l'A. l'ensemble de Vešnave serait, comme les deux premiers cités des favissae, des lieux cachés, ici recouverts de pierres, de dépôts secondaires d'offrandes ; les grottes elles-mêmes pouvaient être des lieux de culte.

J. Rose et Ph. Kreyenbroek tentent une interprétation à partir du zoroastrisme. La première évoque le rite de l'ābzohr pratiqué par une population ordinaire, locale, et retrace la permanence de ce type de culte de l'Antiquité jusqu'à l'époque moderne. Le second tire du livre zoroastrien du Neyrāngestān des informations relatives au culte de l'eau et montre que Vešnave s'inscrit dans une série de lieux de culte de l'eau ou en relation avec l'eau. Il faut donc y voir moins des sanctuaires que des lieux dont le cadre souterrain et la présence permanente de l'eau a suscité des rites, ici pendant plus d'un millénaire. En attendant la publication de cet ensemble exceptionnel, cette première série d'articles apporte déjà beaucoup d'informations.

\section{AUTEURS}

\section{RÉMY BOUCHARLAT}

CNRS, Lyon 